\title{
Effect of Conjugated Linoleic Acid on Reproductive Performance of Gilts
}

\author{
Zdeněk Hadaš ${ }^{1}$, Pavel Nevrkla ${ }^{1} \&$ Eva Václavková ${ }^{2}$ \\ ${ }^{1}$ Department of Animal Breeding, Mendel University in Brno, Brno, Czech Republic \\ ${ }^{2}$ Department of Pig Breeding, Institute of Animal Science, Prague, Czech Republic \\ Correspondence: Zdeněk Hadaš, Department of Animal Breeding, Mendel University in Brno, Zemědělská 1, \\ 61300 Brno, Czech Republic. Tel: 420-545-133-215. E-mail: zdenek.hadas@mendelu.cz
}

\author{
Received: February 24, 2015 Accepted: March 23, 2015 Online Published: May 15, 2015 \\ doi:10.5539/jas.v7n6p120 URL: http://dx.doi.org/10.5539/jas.v7n6p120
}

\begin{abstract}
The aim of this study was to evaluate whether the supplementation of compound feed during rearing and before serving of gilts with conjugated linoleic acid (CLA) influences the organometric parameters of their reproductive system and their reproductive performance. The experimental work was carried out in operating conditions of a production pig farm. Total number of 80 gilts ( 40 gilts in control group and 40 gilts in experimental group) of hybrid combination Czech Large White x Czech Landrace (CLW x CL) were included in the observation. During the experiment the gilts were fed with a control compound feed and an experimental compound feed suplemented with $2 \%$ of CLA for the time of 65 days. After insemination, 20 gilts from both groups were selected randomly, in which organometric parameters of reproductive system were evaluated post mortem. Remaining gilts were tested for their reproductive performance on the first litter. Based on gained results it can be concluded, that the CLA supplementation decreases the mean age of gilts at the time of first service $(\mathrm{P}<0.05)$. The same group recorded trend of higher numbers of ovulated oocytes and collected embryos, however the difference was not statistically significant $(P>0.05)$. Neither statistically significant differences were found in organometric parameters of the reproductive system $(\mathrm{P}>0.05)$. Evaluation of reproductive performance parametres revealed reaching better results in the experimental group $(\mathrm{P}<0.05)$. These findings demonstrate that the supplementation of diet for gilts during rearing with CLA can improve their reproductive performance.
\end{abstract}

Keywords: conjugated linoleic acid, reproductive system, reproductive performance, gilts

\section{Introduction}

One of the essential prerequisits for achievement of profitable lifelong performance of sows is appropriate preparation before their productive period. Breeders goal should therefore be to secure rearing of gilts leading to appropriate body development and onset of reproductive functions. Achievement of optimal results is influenced by several endogenous and exogenous factors. The environmental conditions and especially nutrition are determining for putting the conrol mechanism of sexual activity into operation. The focus of nutrition in breeding gilts is on optimal development of skeleton, muscles and first of all development and function of reproductive organs (Horký, 2014). Quality and appropriate nutrition should ensure reaching sexual maturity, full-fledged function of reproductive organs and optimal development of embryos. Besides necessary energy, amino acids, vitamins and minerals, also fatty acids are substantial components of nutrition. The fatty acids, especially polyunsaturated fatty acids, play an important role in reproductive processes (Wathes et al., 2007). The role of fatty acid in the peri-ovulatory and peri-conception phase of livestock reproduction is multifaceted and effects can be modulated at the endocrine as well as at nutrient provision level (Sturmey et al., 2009). Kim et al. (2007) state that providing fatty acids with specific functions can improve performance of sows by influencing key metabolic pathways. These substances may increase conception rates, embryogenesis, anti-oxidation activity and immune system functions. Meaningful attention has been paid to conjugated linoleic acid (CLA) lately, both in human sphere and in the field of animal nutrition. Stachowska (2008) states that interest in CLA increased with published results on anticancer and lipodystrophic effects, impact on changes in body composition, on diabetes, hypercholesterolemia and on immune system, growth ability and reproduction. Conjugated linoleic acid (CLA) represents a group of positional and geometric isomers of linoleic acid, whose most common sources are milk, dairy products and meat of ruminants. Corino et al. (2009) reported that 
information available on the most appropriate dose and lenght of supplementation of CLA is insufficient. The biggest problem is in using different levels of CLA supplementation, length of supplementation and also limited numbers of animals in individual studies. The role of endogenous stores of fatty acids in reproduction process, oocyte development and embryo pre-implantation in pigs have been studied less intensively than the effect on nutritional value and quality of meat and meat products (e.g. Cordero et al., 2010; Wasilewski et al., 2014). Authors working in the field of reproduction (e.g. Spencer et al., 2004; Castaneda-Gutiérrez et al., 2007; Smits et al., 2011) studied the topic of supplementation with fatty acids in gilts before service or in early phases of gravidity. In their studies they mostly evaluated effects on ovulation and conception rates, numbers of developing embryos, their survival and decreased embryonic mortality. Later analysis of litter size was not described. Therefore the aim of this study was to evaluate the effect of conjugated linoleic acid (CLA) dosed to gilts before service not only on organometric parameters of reproductive system, ovulation rate and embryo development, but also on following results of reproductive performance of gilts on the first litter.

\section{Materials and Methods}

\subsection{Animals and Housing}

Total number of 80 gilts of hybrid combination Czech Large White x Czech Landrace (CLW x CL) were included in the observation. The gilts were divided into two groups of the same number, i.e. 40 gilts in the control and 40 gilts in the experimental group. The gilts were stabled in common operating conditions of rearing house, with each group, i.e. control and experimental, further divided into two group pens of 10 animals. Intake of water and complete compound feed for rearing gilts was ad libitum.

\subsection{Diets and Conjugated Linoleic Acid (CLA)}

The source of synthetic conjugated linoleic acid was the preparation Lutalin (C 18:2 trans - 10 cis - 12) from BASF, Germany. The praparation was added to the experimental compound feed at the level of $2 \%$ by spraying with the use of vacuum mixer. Analysis of compound feed composition was performed in the Laboratory of the Department of Animal Nutrition and Forage Production. Composition and nutrition content of the control and the experimental complete compound feed for gilts are shown in Table 1.

\subsection{Experimental Design}

The experimental work was started when mean weight $108.10 \pm 6.56 \mathrm{~kg}$ was achieved in the experimental group (at the age of $177.20 \pm 12.31$ days) and $109.80 \pm 9.67 \mathrm{~kg}$ in the control group (at the age of $179.20 \pm 9.92$ days). From this moment the experimental group was fed only with complete compound feed for rearing gilts supplemented with conjugated linoleic acid at the level of $2 \%$ for 65 days. After termination of feeding the compound feed, the gilts were inseminated at their second estrus.

\subsubsection{Parameters of Reproductive Organs in Gilts}

Subsequently, 20 gilts from the control group and 20 gilts from the experimental group, randomly selected, were slaughtered at the experimental slaughterhouse of the Institute of Animal Science six days after insemination. Post mortem the reproductive organs were recovered, ovaries were cut off, weighed and the diameter was measured, uterine horns were cut off and their length was measured using a ruler. Embryos were flushed from uterine horns with $40 \mathrm{ml}$ of Dulbecco PBS medium supplemented with $10 \%$ foetal bovine serum (GIBCO ${ }^{\circledR}$, Invitrogene Corporation) warmed to $38.5{ }^{\circ} \mathrm{C}$. The embryos were morphologically examined under stereomicroscope. Following parameters were detected: weight of left and right ovary, diameter of left and right ovary, number of corpora lutea and length of uterine horns. Percentage of fertilized oocytes was calculated from total number of corpora lutea and total number of embryos.

\subsubsection{Reproductive Performance of Gilts}

The remaining gilts, i.e. 20 in the control and 20 in the experimental group, included in the reproduction were intended for evaluation of reproductive performance on the first litter. The gilts were moved to group housing where they stayed till the $108^{\text {th }}$ day of gravidity. One week before estimated term of farrowing they were transfered to individual farrowing pens. After farrowings and after weaning of piglets at the mean age of 28 days, the parameters of reproductive performance were evaluated.

\subsection{Statistical Analysis}

The data were analysed using software QC expert (TriloByte Statistical Software Ltd.). All data were expressed as mean $\pm \mathrm{SD}$. One way ANOVA and the Student's test were used to determine differences between the means of control and experimental group. A probability value of $\mathrm{P}>0.05$ was considered statistically not significant (NS), $\mathrm{P}<0.05$ statistically significant $\left(\mathrm{S}^{*}\right)$. 
Table 1. Composition and nutrition content of the control and the experimental compound feed for gilts

\begin{tabular}{|c|c|c|}
\hline Components proportion in $\%$ & Control compound feed & Experimental compound feed with $2 \%$ CLA \\
\hline Wheat & 39.00 & 39.00 \\
\hline Spring barley & 31.00 & 31.00 \\
\hline Soybean, toasted & 9.00 & 9.00 \\
\hline Rapeseed oil & 2.00 & 0.00 \\
\hline Wheat bran & 5.00 & 5.00 \\
\hline Sugar beet pulp & 5.00 & 5.00 \\
\hline Protein dried fodder & 3.00 & 3.00 \\
\hline Yeast Vitex & 1.50 & 1.50 \\
\hline Conjugated linoleic acid & 0.00 & 2.00 \\
\hline Calcium carbonate & 1.40 & 1.40 \\
\hline Calcium hydrogen phosphate & 1.00 & 1.00 \\
\hline Sodium chloride & 0.40 & 0.40 \\
\hline Copper sulphate pentahydrate (mg/kg) & 23.00 & 23.00 \\
\hline 3 - phytase (PPU) & 500.00 & 500.00 \\
\hline Vitamin A (IU/kg) & 15000 & 15000 \\
\hline Vitamin D 3 (IU/kg) & 1500 & 1500 \\
\hline Vitamin E (IU/kg) & 52.00 & 52.00 \\
\hline Nutrition content $\mathrm{g} / \mathrm{kg}$ & Control compound feed & Experimental compound feed with $2 \%$ CLA \\
\hline Water & 111.53 & 113.75 \\
\hline Dry matter & 888.47 & 886.25 \\
\hline Nitrogen & 23.38 & 23.45 \\
\hline Crude protein & 146.13 & 146.56 \\
\hline Indigestible $\mathrm{N}$ - substances & 17.25 & 18.00 \\
\hline Digestible N - substances & 128.88 & 128.56 \\
\hline Roughage & 37.33 & 37.00 \\
\hline Fat & 48.59 & 45.78 \\
\hline Ash & 57.43 & 57.13 \\
\hline Sacharose & 21.77 & 19.56 \\
\hline Starch & 438.90 & 434.26 \\
\hline Lysine & 7.55 & 7.55 \\
\hline Methionine & 2.41 & 2.41 \\
\hline Met + cys & 4.79 & 4.79 \\
\hline Threonine & 4.94 & 4.94 \\
\hline Tryptofan & 1.66 & 1.66 \\
\hline Calcium & 0.69 & 0.69 \\
\hline Total phosphorus & 4.52 & 4.52 \\
\hline Digestible phosphorus & 1.19 & 1.19 \\
\hline Sodium & 1.64 & 1.64 \\
\hline $\mathrm{ME}(\mathrm{MJ} / \mathrm{kg})$ & 13.36 & 13.22 \\
\hline
\end{tabular}

\section{Results}

\subsection{Parameters of Reproductive Organs in Gilts}

The results of parameters of reproductive organs in gilts are shown in Table 2. Higher weight and diameter of ovaries were found in the experimental group, however without statistically significant difference $(P>0.05)$. The length of uterine horns was also measured in the experiment. Longer right uterine horn was found in the control group but left uterus was longer in the experimental group $(\mathrm{P}>0.05)$. The number of corpora lutea $(\mathrm{CL})$ on the 
right ovary was higher in the control group of gilts, on the contrary on the left ovary the number was higher in the experimental group. Overall, the ovulation rate was higher in the gilts of the experimental group by nearly two oocytes. Also the number of flushed embryos was higher in gilts of the experimental group. Although the differences between groups are not statistically significant $(\mathrm{P}>0.05)$, there is an evident trend of higher number of ovulated oocytes and collected embryos after inclusion of CLA into feed ration for gilts.

In the gilts slaughtered six days after the first insemination, higher ratio of fertilized oocytes (flushed embryos) and corpora lutea was found in the control group than in the experimental group $(\mathrm{P}>0.05)$. The relations between selected organometric parameters of reproductive system were calculated as correlations of all measured values, regardless of differences between the experimental and the control group. Highly significant correlations $(\mathrm{P}<0.01)$ were observed between the ovary weight and the number of corpora lutea $(\mathrm{r}=0.69)$, ovary weight and number of embryos $(r=0.42)$, ovary diameter and number of corpora lutea $(r=0.49)$ and ovary diameter and number of embryos $(\mathrm{r}=0.34)$.

Table 2. Basic statistical characteristics of parameters of reproductive organs in gilts

\begin{tabular}{lllll}
\hline \multirow{2}{*}{ Parameter } & & \multicolumn{2}{c}{ Group } & Statistical significance \\
\cline { 3 - 4 } & & Control & Experimental & \\
\hline Ovary weight $(\mathrm{g})$ & Right & $5.38 \pm 2.18$ & $6.74 \pm 2.52$ & NS \\
Ovary diameter $(\mathrm{cm})$ & Left & $6.37 \pm 3.20$ & $8.50 \pm 2.84$ & NS \\
& Right & $2.75 \pm 0.56$ & $3.14 \pm 0.48$ & NS \\
Number of corpora lutea & Left & $2.97 \pm 0.54$ & $3.08 \pm 0.59$ & NS \\
Uterine horn length $(\mathrm{cm})$ & Right ovary & $7.17 \pm 1.94$ & $6.20 \pm 2.59$ & NS \\
& Left ovary & $7.17 \pm 2.31$ & $10.20 \pm 3.35$ & NS \\
\hline Total number of embryos & Right & $123.17 \pm 19.03$ & $114.20 \pm 22.59$ & NS \\
Fertilized oocytes $(\%)$ & Left & $124.33 \pm 31.40$ & $124.40 \pm 15.68$ & NS \\
\hline
\end{tabular}

Note. $\mathrm{NS}=$ Difference between values is not statistically significant $(\mathrm{P}>0.05)$.

\subsection{Reproductive Performance of Gilts on the First Litter}

Age of gilts at the time of first service was calculated from the dates of birth and dates of first insemination. The gilts in the control group were inseminated at the mean age of $248.60 \pm 20.80$ days and gilts in the experimental group at the age of $245.40 \pm 16.50$ days. Statistically significant difference $(\mathrm{P}<0.05)$ between the evaluated groups of sows counted 3.2 days in favor of gilts fed with CLA supplementation. Results of conception in gilts are shown in Figure 1. These results speak in favor of the experimental group, with confirmed gravidity in 16 gilts after the $1^{\text {st }}$ insemination, in 3 gilts after the $2^{\text {nd }}$ insemination and in one gilt the $3^{\text {rd }}$ insemination was necessary. On the contrary, in the control group, gravidity after the $1^{\text {st }}$ insemination was confirmed in 14 gilts, after the $2^{\text {nd }}$ insemination in 3 gilts and the $3^{\text {rd }}$ insemination was necessary in 3 gilts. 


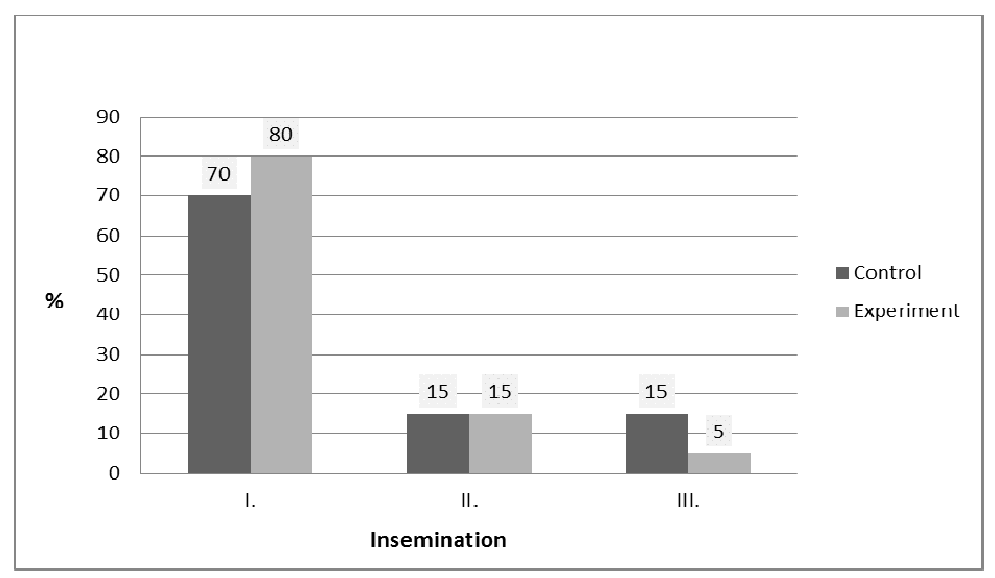

Figure 1. Conception in gilts

Achieved results of reproductive performance are presented in Table 3. It can be concluded that phenotypic level of reproductive performance in gilts was significantly $(\mathrm{P}<0.05)$ influenced by addition of conjugated linoleic acid to feed ration before service. Reached mean values of total numbers of born piglets indicate that litter size was significantly influenced $(\mathrm{P}<0.05)$ by supplementation with CLA. Results of number of live-born piglets again speak in favor of the experimental group, with statistically significant difference $(\mathrm{P}<0.05)$ of 1.5 piglet. Comparison of numbers of stillborn piglets also showed better results in the experimental group $(\mathrm{P}<0.05)$. Another evaluated parameter, number of weaned piglets, was also higher in the gilts with feed ration supplemented with conjugated linoleic acid. The difference in number of weaned piglets was 1.27 and was found statistically significant $(\mathrm{P}<0.05)$. These findings demonstrate that the supplementation of diet for rearing gilts with CLA can improve their reproductive performance.

Table 3. Basic statistical characteristics of reproductive parametres in gilts on the first litter

\begin{tabular}{llll}
\hline \multirow{2}{*}{ Parameter } & \multicolumn{2}{c}{ Group } & \multirow{2}{*}{ Statistical significance } \\
\cline { 2 - 3 } & Control & Experimental & \\
\hline Total number of piglets (pcs/litter) & $9.89 \pm 4.03$ & $10.58 \pm 4.56$ & $\mathrm{~S}^{*}$ \\
Number of live-born piglets (pcs/litter) & $8.40 \pm 3.90$ & $9.91 \pm 4.14$ & $\mathrm{~S}^{*}$ \\
Number of stillborn piglets (pcs/litter) & $1.46 \pm 3.38$ & $0.67 \pm 0.98$ & $\mathrm{~S}^{*}$ \\
Number of weaned piglets (pcs/litter) & $7.73 \pm 3.37$ & $9.00 \pm 3.30$ & $\mathrm{~S}^{*}$ \\
\hline
\end{tabular}

Note. $\mathrm{S} *=$ Difference between values is statistically significant $(\mathrm{P}<0.05)$.

\section{Discussion}

\subsection{Parameters of Reproductive Organs in Gilts}

The results of our study did not confirm an effect of conjugated linoleic acid supplement in compound feed for rearing of gilts on the parameters of reproductive organs. However there was an evident trend in ovulation of higher numbers of oocytes and collected embryos. Castaneda-Gutiérrez et al. (2007) state that mechanisms, by which CLA influences reproduction, may include better follicular development. A positive effect of supplementation with fatty acids was confirmed by Kojima et al. (1997), who found the highest number of corpora lutea in gilts, whose diet was enriched in PUFA $(\mathrm{P}<0.05)$. Based on achieved results they say that feed mixtures enriched in unsaturated fatty acids may be efficient in increasing of ovulation rate. Brazle et al. (2009) conducted a study on evaluation of effect of PUFA supplementation length on embryonic development. PUFA supplementation was dosed to gilts with approximate age of 170 days till the $40^{\text {th }}-43^{\text {rd }}$ day of gravidity, in the second group of gilts from the age of 150 days for 33 days. In both groups the same dose of PUFA was used, i.e. $1.5 \%$. Subsequently, corpora lutea and embryos were evaluated. Numbers of corpora lutea were not influenced, but differences were found in the numbers of developing embryos as same as their composition. Authors state that nutrition of gilts supplemented with fatty acids changed composition of embryos and that supplementation 
with n-3 fatty acids can influence survival of embryos. On the contrary, Estienne et al. (2006) did not confirm an effect of $1 \%$ addition of omega-3 polyunsaturated fatty acid source to gilts before insemination on ovulation rate and numbers of embryos. Perez et al. (1995) also evaluated the effect of dietary n-3 PUFA on embryo development. They did not find effect on the number of corpora lutea and number of embryos. The correlations between monitored morphometric parameters of reproductive system were evaluated in our experiment. Dybala et al. (2008) calculated significant correlations $(\mathrm{P}<0.01)$ between uterus weight and uterine horns length, uterus capacity and ovaries weight. Also the study of Brüssow et al. (2004) confirmed correlation between numbers of corpora lutea and ovarian weight $(\mathrm{P}<0.01)$.

\subsection{Reproductive Performance of Gilts on the First Litter}

The results of the study proved statistically significant $(\mathrm{P}<0.05)$ positive effect of CLA supplementation dosed during rearing on reproductive performance of gilts on the first litter. Mattos et al. (2000) published conclusions that fatty acids in general can positively influence reproduction via improvement of energy balance and increased levels of reproductive hormone precursors. According to the authors, CLA contributes to suppression of $F_{2 a l f a}$ prostaglandin synthesis in uterine endometrium, which is an antagonist to progesterone produced by the

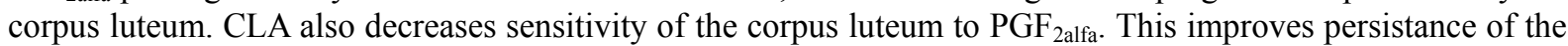
corpus luteum and pregnancy maintenance in early stages and thus decreases probability of early embryonic mortality. Increased embryonic survival is described also by Webel et al. (2003) and Perez et al. (1995) who recorded an increase of early embryonic survival in gilts fed with a source of omega-3 fatty acids. Spencer et al. (2004) performed evaluation of litter size after feeding gilts before inclusion into reproduction with a source of omega-3 fatty acids (1.5\%) for 30 days and confirmed increased litter size. Also Smits et al. (2011) found positive effect of n-3 PUFA addition to nutrition of gilts before service on litter size. Statistically significant difference $(\mathrm{P}<0.05)$ was found in the total number of born piglets $(10.7 \mathrm{vs} 9.7)$ and in the number of live-born piglets (10.2 vs 9.3). Positive effect of omega-3 fatty acids was recorded also by Reese (2003), when a preparation dosed for 30 days before service influenced the total number of born piglets (8.7 vs 7.9$)$ as well as the number of live-born piglets ( 8.3 vs 7.4$)$ and proved decreased mortality before weaning $(10.2 \%$ vs $11.7 \%$; $\mathrm{P}$ $<0.05)$.

\section{Conclusion}

The results of our study proved that the supplementation of compound feed for rearing gilts with conjugated linoleic acid can influence reproductive performance. This indicates a potential possibility of using CLA as an effective nutritional supplement for improving results in the area of pig reproduction. However many other factors play important role in pig reproduction and must be taken into account.

\section{Acknowledgements}

This study was supported by the project No. QI 111A166 of the Ministry of Agriculture of the Czech Republic.

\section{References}

Brazle, A. E., Johnson, B. J., Webel, S. K., Rathbun, T. J., \& Davis, D. L. (2009). Omega-3 fatty acids in the gravid pig uterus as affected by maternal supplementation with omega-3 fatty acids. Journal of Animal Science, 87, 994-1002. http://dx.doi.org/10.2527/jas.2007-0626

Brüssow, K. P., Egerszegi, I., Ratky, J., Soos, F., Casado, P. G., Tuchscherer, A., \& Toth, P. (2004). Organometric data of the reproductive tract in cycling and early pregnant Hungarian Mangalica Pigs. Archiv fur Tierzucht, 47, 585-594.

Castaneda-Gutiérrez, E., Benefield, B. C., De Veth, M. J., Santos, N. R., Gilbert, R. O., Butler, W. R., \& Bauman, D. E. (2007). Evaluation of the mechanism of action of conjugated linoleic acid isomers on reproduction in dairy cows. Journal of Dairy Science, 90, 4253-4264. http://dx.doi.org/10.3168/jds.2007-0117

Cordero, G., Isabel, B., Menoyo, D., Daza, A., Morales, J., Piniero, C., \& Lopez-Bote, C. J. (2010). Dietary CLA alters intramuscular fat and fatty acid composition of pig skeletal muscle and subcutaneous adipose tissue. Meat Science, 85, 235-239. http://dx.doi.org/10.1016/j.meatsci.2010.01.004

Corino, C., Pastorelli, G., Rosi, F., Bontempo, V., \& Rossi, R. (2009). Effect of dietary conjugated linoleic acid supplementation in sows on performance and immunoglobulin concetration in piglets. Journal of Animal Science, 87, 2299-2305. http://dx.doi.org/10.2527/jas.2008-1232

Dybala, J., Zmudzinska, A., Wisniewska, J., Biegniewska, M., \& Jelinska, A. (2008). Relationship between some morphometric traits of reproductive system of primiparous sows and their fertility. Research in Pig Breeding, 2, 9-13. 
Estienne, M. J., Harper, A. F., \& Estienne, C. E. (2006). Effects of dietary supplementation with omega-3 polyunsaturated fatty acids on some reproductive characteristics in gilts. Reproductive Biology, 6, 231-241.

Horký, P. (2014). Influence of increased dietary selenium on glutathione peroxidase activity and glutathione concentration in erythrocytes of lactating sows. Annals of Animal Science, 14, 869-882. http://dx.doi.org/10.2478/aoas-2014-0056

Kim, S. W., Mateo, R. D., Yin, Y. L., \& Wu, G. (2007). Functional amino acids and fatty acids for enhancing production performance of sows and piglets. Asian-Australasian Journal of Animal Science, 20, 295-306. http://dx.doi.org/10.5713/ajas.2007.295

Kojima, T., Zeniya, Y., Aoyama, T., Kondo, A., \& Yoshino, J. (1997). Dietary administration on fatty acids-enriched mold dried cell containing gamma linolenic acid to female pigs improves ovulation rate and embryo quality in summer. Journal of Reproduction and Development, 43, 121-127. http://dx.doi.org/10.1262/jrd.43.121

Mattos, R., Staples, C. R., \& Thatcher, W. W. (2000). Effects of dietary fatty acid on reproduction in ruminants. Reviews of Reproduction, 5, 38-45. http://dx.doi.org/10.1530/ror.0.0050038

Perez, R. A., Lindemann, M. D., Kornegay, E. T., Harper, A. F., \& Watkins, B. A. (1995). Role of dietary lipids on fetal tissue fatty acid composition and fetal survival in swine at 42 days of gestation. Journal of Animal Science, 7, 1372-1380.

Reese, D. (2003). Omega-3 Fatty acids and swine reproduction - A Review. Nebraska Swine Reports, 66, 29-33. Retrieved from http://digitalcommons.unl.edu/cgi/viewcontent.cgi?article=1065\&context=coopext_swine

Smits, R. J., Luxford, B. G., Mitchell, M., \& Nottle, M. B. (2011). Sow liter size is increased in the subsequent parity when lactating sows are fed diets containing n-3 fatty acids from fish oil. Journal of Animal Science, 89, 2731-2738. http://dx.doi.org/10.2527/jas.2010-3593

Spencer, J. D., Wilson, L., Webel, S. K., Moser, R. L., \& Webel, D. M. (2004). Effect of feeding protected n-3 polyunsaturated fatty acids $\left(\right.$ Fertilium $^{\mathrm{TM}}$ ) on litter size in gilts. Journal of Animal Science, 82, 81.

Stachowska, E. (2008). Conjugated dienes of linoleic acid and tumorgenesis. Annales Academiae Medicae Stetinensis, 54, 122-125.

Sturmey, R. G., Reis, A., Leese, H. J., \& McEvoy, T. G. (2009). Role of fatty acids in energy provision during oocyte maturation and early embryo development. Reproduction in Domestic Animals, 44(Suppl. 3), 50-58. http://dx.doi.org/10.1111/j.1439-0531.2009.01402.x

Wasilewski, P. D., Michalska, G., Cechova, M., \& Nevrkla, P. (2014). Change of the backfat fatty acid profile of crossbred pigs fed with the fodder with adition of sunflower oil and conjugated linoleic acid. Bulgarian Journal of Agricultural Science, 20, 226-231.

Wathes, D. C., Abayasekara, D. R., \& Aitken, R. J. (2007). Polyunsaturated fatty acids in male and female reproduction. Biology of Reproduction, 77, 190-201. http://dx.doi.org/10.1095/biolreprod.107.060558

Webel, S. K., Otto, E. R., Webel, D. M., Moser, R. L., Spencer, J. D., \& Orr, D. E. (2003). Effect of protected n-3 polyunsatured fatty acids (Fertilium ${ }^{\mathrm{TM}}$ ) on litter size in sows. Journal of Animal Science, 81, 18.

\section{Copyrights}

Copyright for this article is retained by the author(s), with first publication rights granted to the journal.

This is an open-access article distributed under the terms and conditions of the Creative Commons Attribution license (http://creativecommons.org/licenses/by/3.0/). 